\title{
Genetic Variability, Heritability, Genetic advance and Divergence in Ethiopian Cowpea [Vigna unguiculata (L) Walp] Landraces
}

Fantaye Belay ( $\sim$ fantaye933@gmail.com )

Tigray Agricultural Research Institute (TARI), Abergelle Agricultural Research Center P. O. Box 44, Abi-Adi, Ethiopia

\section{Kibrom Fischa}

Tigray Agricultural Research Institute (TARI), Abergelle Agricultural Research Center P. O. Box 44, Abi-Adi, Ethiopia

\section{Research Article}

Keywords: Accession, Agronomic traits, Cluster, Variability, Vigna unguiculata

Posted Date: June 22nd, 2020

DOI: https://doi.org/10.21203/rs.3.rs-37282/v1

License: (c) (i) This work is licensed under a Creative Commons Attribution 4.0 International License. Read Full License 


\title{
Genetic Variability, Heritability, Genetic advance and Divergence in Ethiopian Cowpea [Vigna unguiculata $(\mathbf{L})$ Walp] Landraces
}

Fantaye Belay* and Kibrom Fiseha

Tigray Agricultural Research Institute (TARI), Abergelle Agricultural Research Center P. O. Box 44, Abi-Adi, Ethiopia.

*Corresponding Author:

E-mail: fantaye933@gmail.com, Mobile: +251 912725888, Tel: +251-34 4 46-07-41

Abi-Adi, Ethiopia

\begin{abstract}
Information on genetic variability in cowpea germplasm is important for crop improvement and for efficient utilization of the existing genetic resources. Hence, the objectives of the present investigation were to estimate genetic variability, heritability, genetic advance and to identify divergent parents from distantly related clusters among Ethiopian cowpea accessions. The field experiment was carried out using 42 accessions at Abergelle Agricultural Research Center on station during the 2019 cropping season. Data were collected for 8 agronomic traits and analysis of variance revealed significant differences $(p<0.01)$ among the accessions for the traits studied. Seed yield had higher genotypic coefficient of variation (GCV) and phenotypic coefficient of variation (PCV) coupled with the highest genetic advance as percent of mean (100\%). All the traits had moderate (68.01) to very high $(99.98 \%)$ broad sense heritability. Further, high heritability coupled with high genetic advance as percent of mean was attained for days to flowering, grain filling period, plant height, pod length, seed yield and thousand seed weight reflecting the presence of additive gene action for the expression of these traits and improvement of these traits could be done through selection. The cluster analysis based on agronomic traits revealed four distinct groups at $90 \%$ similarity level. The highest inter cluster $\mathrm{D}_{2}$ was recorded between cluster III and cluster IV ( $\mathrm{D}_{2}=133.69$ units). The range of inter cluster distance was 15.25 to 133.69 units, respectively. In conclusion, the high genetic distance revealed among clusters has to be exploited via crossing and selection of the most divergent parents for future cowpea improvement program.
\end{abstract}

Keywords: Accession, Agronomic traits, Cluster, Variability, Vigna unguiculata

\section{INTRODUCTION}

Cowpea [Vigna unguiculata (L.) Walp., Fabaceae $(2 \mathrm{n}=2 \mathrm{x}=22)$ ] is an important dual purpose (food and forage) legume crop widely grown under low input production systems and in arid and semi-arid agro-ecologies of the world (Timko and Singh, 2008; Srivastava et al., 2016). It is predominantly a self-pollinated crop, with natural cross-pollination up to one percent. Cowpea could play significant role in mitigating malnutrition such as micronutrient deficiencies for poor 
farmers of Sub-Saharan countries (Menssena et al., 2017). It has distinct features such as its earliness in maturity, tolerance to drought, heat, acidity and low fertility, and seed types with high protein content and low cooking time (Tariku, 2018). It is well adapted to the drier regions of the tropics, where other food legumes do not perform well. Cowpea is eaten in the form of dry seeds, green pods, green seeds and tender green leaves. As a pulse crop, cowpea provides more than half the plant protein for human diets in some areas of semi-arid tropics is being referred to as “poor-man's meat” (Ravelombola et al., 2016).

Cowpea grain typically contains $230-250 \mathrm{~g} / \mathrm{kg}$ crude protein $(\mathrm{CP})$ and $500-670 \mathrm{~g} / \mathrm{kg}$ starch on a dry matter (DM) basis and cowpea forage, i.e. the crop residue after harvesting grain, $210 \mathrm{~g} \mathrm{CP}$ and $600 \mathrm{~g}$ digestible dry matter per $\mathrm{kg} \mathrm{DM}$. These excellent nutritional qualities of cowpea make as one of the potential crop as a component of the cropping system and livelihood for the smallholder farmers living in drier regions of Ethiopia (MoANR, 2016). Thus, this crop can contribute greatly towards meeting the food requirement of people in areas where food security and malnutrition are major challenges. Regardless of the various merits of cowpea in Ethiopia, the national production and productivity is far below the potential due to several abiotic and biotic constraints among which drought, insect pests, parasitic weeds and virus facing cowpea production to have resulted in a very low yield (Selamawit et al., 2020).

Though, Ethiopia is one of the centers of origin and/or diversity of cowpea (Vavilov, 1951) and more than $66.5 \%$ of arable land is very suitable for cowpea production (CCRP, 2015), the country has not been in a position to be benefited from international and continental cowpea improvement program or from the national pulse crops research. This is because low attention in research for cowpea is given as compared to other pulse crops. To harness the potential of cowpea landraces grown in Ethiopia baseline information regarding cowpea production status in the country /baseline information has been generated. Greater the variability in a population, there is the greater chance for effective selection for anticipated varieties. However, very few studies have been conducted on cowpea genetic variability using quantitative traits employed in the country. Hence, the objectives of the present study were to assess variability, heritability, genetic advance and to identify divergent parents from distantly related clusters for the future cowpea improvement program. 


\section{MATERIALS AND METHODS}

\section{Description of the experimental site}

The field trial was conducted at Tanqua Abergelle district central zone of Tigray region, northern Ethiopia during the 2019 main cropping season. The site (Mearey) is located at about $903 \mathrm{~km}$ north of Addis Ababa and $120 \mathrm{~km}$ south west of Mekelle city. It has an approximate geographical coordinates of 13014'06" N latitude and 38058'50" E longitudes having an altitude 1560 meter above sea level (Figure-1). The area is characterized by an erratic rainfall pattern with "kola" agro climatic zone. The rainy season is mono modal pattern concentrated in one season during the summer (July to August) and receives from 350- $600 \mathrm{~mm}$, annual precipitation. The mean minimum and maximum temperature of the area ranges from $18-420 \mathrm{C}$, respectively (Belay et al., 2017). The soil texture of the specific site of the study area is sandy clay textural class with high available $\mathrm{P}(13.82 \mathrm{mg} \mathrm{kg-1)}$, very low in total $\mathrm{N}(0.08 \%)$ and low organic matter $(0.72 \%)$ with a neutral $\mathrm{pH}$ of 7.18 .

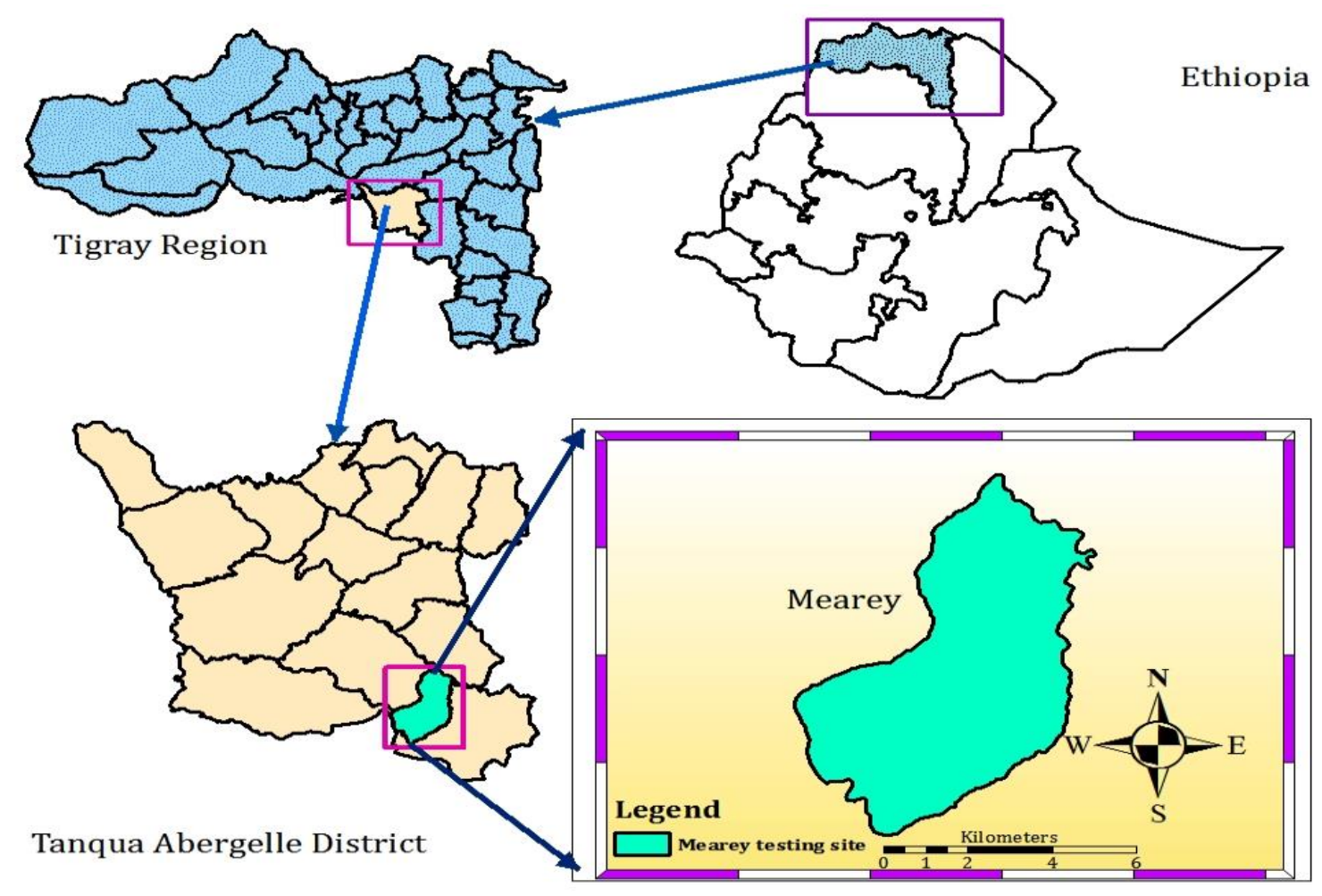

Figure 1: Map of the study site 


\section{Description of the planting materials}

The experimental plant materials comprised a total of 42 cowpea accessions/local landraces along with one released variety Bekur as a check was used in this study. The landraces were Ethiopian origin kindly provided by the Ethiopian Institute of Biodiversity (EIB) collected from different agro-ecological regions of the country, varying in altitude, rainfall, temperature, and soil type. The accession numbers and source of the genotypes are presented in Table 1.

Table 1: Description of the cowpea accessions used in the study.

\begin{tabular}{|c|c|c|c|c|c|c|}
\hline $\begin{array}{l}\text { S } \\
\text { № }\end{array}$ & Accessions & $\begin{array}{l}\text { Seed size } \\
\text { description }\end{array}$ & $\begin{array}{l}\text { Seed coat } \\
\text { color }\end{array}$ & $\begin{array}{l}\text { Growth } \\
\text { habit }\end{array}$ & $\begin{array}{l}\text { Collection } \\
\text { region }\end{array}$ & Source \\
\hline 1 & Adongor/ local & Small & White & Decumbent & Tigray & Abergelle ARC \\
\hline 2 & Acc\#216747 & Small & White & Climbing & Gambela & EIB \\
\hline 3 & Acc\#208643 & Small & Brown & Decumbent & Oromia & EIB \\
\hline 4 & Acc\#211441 & Small & Brown & Decumbent & Oromia & EIB \\
\hline 5 & Acc\#26058 & Medium & White & Decumbent & Tigray & EIB \\
\hline 6 & Acc\#211443 & Small* & Light white & Decumbent & Oromia & EIB \\
\hline 7 & Acc\#211440 & Small & Dark white & Climbing & Oromia & EIB \\
\hline 8 & Acc\#216749 & Small & Silver & Climbing & Gambela & EIB \\
\hline 9 & Acc\#235122 & Small & White & Decumbent & Tigray & EIB \\
\hline 10 & Acc\#210856 & Small & light gold & Climbing & Oromia & EIB \\
\hline 11 & Acc\#223402 & Small & White & Climbing & Oromia & EIB \\
\hline 12 & Acc\#211429 & Small & Black & Climbing & SNNP & EIB \\
\hline 13 & Acc\#223403 & Small & Light ranger & Climbing & Oromia & EIB \\
\hline 14 & Acc\#221727 & Small & White & Climbing & Tigray & EIB \\
\hline 15 & Acc\#210857 & Small & Gray & Climbing & Oromia & EIB \\
\hline 16 & Acc\#211446 & Small & White & Decumbent & Oromia & EIB \\
\hline 17 & Acc\#211557 & $\operatorname{Large}^{* * * *}$ & White & Decumbent & Amhara & EIB \\
\hline 18 & Acc\#211436 & Small & White & Climbing & Amhara & EIB \\
\hline 19 & Acc\#211491 & Small & Light white & Decumbent & SNNP & EIB \\
\hline 20 & Acc\#215821 & Small & Red cherry & Decumbent & Gambela & EIB \\
\hline 21 & Acc\#227104 & Small & White & Decumbent & SNNP & EIB \\
\hline 22 & Acc\#26060 & Small & Light white & Decumbent & Tigray & EIB \\
\hline 23 & Acc\#230575 & Small & Back & Decumbent & Amhara & EIB \\
\hline 24 & Acc $\# 211433$ & Small & Red cherry & Climbing & B/Gumuz & EIB \\
\hline 25 & Acc\#222890 & Small & White & Climbing & Gambela & EIB \\
\hline 26 & Acc\#211490 & Medium** & Red cherry & Decumbent & SNNP & EIB \\
\hline 27 & Acc\#208776 & Small & Black & Climbing & Oromia & EIB \\
\hline 28 & Acc\#211430 & Small & Black & Decumbent & SNNP & EIB \\
\hline 29 & Acc\#222891 & Small & White & Climbing & Gambela & EIB \\
\hline
\end{tabular}




\begin{tabular}{lllllll}
\hline 30 & Acc\#211444 & Small & Red cherry & Decumbent & Oromia & EIB \\
31 & Acc\#26059 & Small & Light white & Climbing & Tigray & EIB \\
32 & Acc\#216748 & Small & White & Decumbent & Gambela & EIB \\
33 & Acc\#211447 & Small & Light white & Decumbent & B/Gumuz & EIB \\
34 & Acc\#211384 & Small & White & Decumbent & Amhara & EIB \\
35 & Acc\#216746 & Large & White & Decumbent & Gambela & EIB \\
36 & Acc\#228624 & Small & Light ranger & Climbing & Amhara & EIB \\
37 & Acc\#29597 & Small & White & Climbing & B/Gumuz & EIB \\
38 & Acc\#215762 & Small & White & Decumbent & Amhara & EIB \\
39 & Acc\#215760 & Small & Brown & Climbing & Amhara & EIB \\
40 & Acc\#211383 & Small & Brown & Climbing & Amhara & EIB \\
41 & Acc\#215761 & Small & Reddish & Climbing & Amhara & EIB \\
42 & Bekur/ released & Small & Brown & Decumbent & Amhara & Sirinka \\
& variety & & & & & ARC \\
\hline
\end{tabular}

Where: $\mathrm{EIB}=$ Ethiopian Institute of Biodiversity, $\mathrm{ARC}=$ Agricultural Research Center

$*$ Small $=<15 \mathrm{~g} / 100$-seed weight, $* *$ Medium $=15-19 \mathrm{~g} / 100$-seed weight, $* *$ Large $=>20 \mathrm{~g} / 100$ seed weight; (Omoigui et al., 2006).

\section{Experimental design and crop management}

The experiment was laid out using $(6,7) \alpha$ - lattice design with three replications. The plot size was $7.2 \mathrm{~m} 2(4 \mathrm{~m} \times 1.8 \mathrm{~m})$ with three rows of inter-row $(60 \mathrm{~cm})$ and intra-row $(20 \mathrm{~cm})$ spacing's. The distance between plots, intra-blocks, and replications was $0.5 \mathrm{~m}, 1 \mathrm{~m}$ and $1.5 \mathrm{~m}$, respectively. Blended NPSZnB fertilizer was applied at the rate of $100 \mathrm{~kg}$ ha-1 during planting. All other agronomic managements were applied uniformly as per national recommendation for cowpea.

\section{Data collection:}

Some phonological (days to flowering, days to maturity, grain filling period), morphological (plant height, pod length) and yield and yield related trait (seed yield, thousand seed weight, number of seeds per pod) of each genotype was collected following the descriptor for cowpea developed by the International Board for Plant Genetic Resources (IBPGR, 1983). The data collected on plot basis were days to flowering, days to maturity, grain filling period (days), thousand seed weight (g) and seed yield (g). In addition, the data collected on individual plant basis were plant height $(\mathrm{cm})$, pod length $(\mathrm{cm})$ and number of seeds per pod. For single plant based traits, the average of data from the five random samples of plants per plot were used and seed yield per plot in grams was converted to $\mathrm{kg}$ ha-1 for analyses. 


\section{Data analysis:}

Data for agronomic traits were subjected to analysis of variances (ANOVA) for lattice design procedures of SAS Version 9.2 (SAS Institute Inc., 2010) to test the presence of significant differences among genotypes. Variability among accessions was estimated using genotypic variances and coefficients of variations as suggested by Burton and De vane (1953) and these components of variance $\left(\delta_{2} \mathrm{p}, \delta_{2} \mathrm{e}, \delta_{2} \mathrm{~g}\right)$ were used for the estimation of coefficients of variation (PCV, GCV) as described by Singh and Chaudhary (1985).

1. Genotypic variance, $G V=\frac{(M S g-M S e)}{\mathbf{r}}$, where $M S g=$ mean square of genotypes, $M S e=$ mean square of error (environmental variance or $\delta_{2} \mathrm{e}$ ), and $r=$ number of replications;

2. Phenotypic variance, $P V=G V+M S e$, where $G V=$ genotypic variance and $M S e=$ mean square of error;

3. Genotypic coefficient of variation, $G C V=(\sqrt{G V}) / x \times 100$, where $G V=$ genotypic variance and $x=$ grand mean of the character;

4. Phenotypic coefficient of variation, $P C V=(\sqrt{P V}) / x \times 100$, where $P V=$ phenotypic variance and $x=$ mean of the character.

5. Broad sense heritability $\left(\mathrm{H}_{2}\right)$ of all traits was calculated according to the formula as described by Allard (1960) as follows: $H_{2}=\left[\left(\sigma_{2} g\right) /\left(\sigma_{2} p\right)\right] \times 100$, where $\sigma_{2} g$ and $\sigma_{2} p$ are genotypic and phenotypic variances respectively.

6. Genetic Advance (GA) for selection intensity (K) at 5\% was computed according to Allard (1960) as given here: $\mathrm{GA}=\mathrm{K} \sigma 2 \mathrm{pH}_{2}$, where, $\mathrm{GA}=$ expected genetic advance, $\mathrm{K}=$ the standardized selection differential at $5 \%$ selection intensity $(\mathrm{K}=2.063)$, б2p $=$ is phenotypic standard deviation on mean basis and $\mathrm{H}_{2}=$ heritability in broad sense.

7. Genetic advance as percentage of population means (GAM) was also estimated with the methods described by Johnson et al. (1955) to compare the extent of the predicted advance of different traits under selection using the following formula: GAM $=\frac{\operatorname{GAx} 100}{\mathbf{x}}$, where GA $=$ genetic advance under selection and $\mathrm{x}=$ mean of the population.

8. Hierarchical (Ward, 1963) cluster analysis was performed to group accessions and construct a dendrogram by Ward's method by using SAS software. The measure of dissimilarity was Euclidean distance. The average inter-cluster distance was calculated using the generalized 
Mahalanobis's D2 statistics (Mahalanobis, 1936). The R2 (RSQ), Cubic Clustering Criteria (CCC), pseudo-F statistics (PSF) and pseudo-T2 statistics were considered for defining optimum cluster numbers (Milligan and Cooper, 1985). The contributions of each of the traits to divergence were estimated as described as Sharma (1998) with the formula

$\left[\mathrm{CTIC}=\frac{\mathrm{SD}}{\mathbf{x}}\right]$, where SD and $\mathbf{x}$ are the standard deviation and mean performance of each trait, respectively.

\section{RESULTS AND DISCUSSION}

\section{Genetic variability}

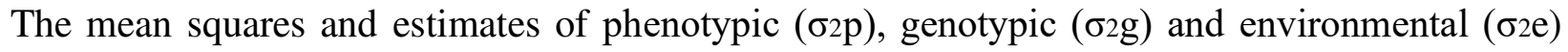
variances, phenotypic coefficients of variation (PCV) and genotypic coefficients of variation (GCV) along with the mean of traits investigated are presented in Table 2. The analysis of variance showed that the mean squares for the genotypes were highly significant $(\mathrm{p}<0.01)$ for all agronomic traits indicating presence of adequate variability among Ethiopian cowpea accessions. Genetic variance ranged from 1.68 for number of seeds per pod to 590157.45 for seed yield (kg ha-1) while phenotypic variance values ranged from 2.47 to 590283.96 for seed yield (kg ha-1). The GCV ranged from $6.90 \%$ for days to maturity to $48.80 \%$ for seed yield. Similarly, PCV ranges from $7.45 \%$ for days to maturity to $48.81 \%$ for seed yield. The GCV and PCV values are normally categorized as low $(<10 \%)$, moderate $(10-20 \%)$ and high $(>20 \%)$ as indicated by Deshmukh et al. (1986).

The highest phenotypic coefficient of variation (PVC) and genotypic coefficient of variation (GCV) were recorded for seed yield $(48.81,48.80)$ followed by 1000 -seed weight $(33.36,33.37)$ and grain filling period $(23.25,21.15)$ while low PVCs and GVCs were recorded for days to maturity $(7.45,6.90)$, number of seeds pod-1 $(13.53,11.16)$, plant height $(13.96,13.88)$, days to flowering $(15.01,14.80)$ and pod length $(17.82,16.44)$, respectively. The present study suggests that the phenotypic coefficient of variation (PCV) was relatively higher than the corresponding genotypic coefficient of variation (GCV). However, the difference between PCV and GCV were narrow indicating little influence of environment on the expression of these traits and considerable amount of variation was observed for the traits studied. 
The results of the study was in conformity with the findings of Reshma et al. (2019) who reported high value of PCV and GCV for seed yield per plant, 100-seed weight and number of pods per plant. Additionally, Manggoel el al. (2012) and Mofokeng et al. (2020) also reported high PCV and GCV for days to flowering, number of branches, pod number per plant, pod weight per plant, seed number per pod, hundred seed weight and seed yield in cowpea.

\section{Broad sense heritability}

The estimate of broad sense heritability for all the traits under study is presented in Table 2. All agronomic traits recorded high heritability ranged from 68.01(number of seeds per pod) to 99.98\% (seed yield) indicating additive gene effects control the expression of the traits. Heritability is classified as low $(<40 \%)$, medium (40-59\%), moderately high $(60-79 \%)$ and very high ( $\geq 80 \%$ ), according to Singh (2001). In the current study, the highest estimates of broad sense heritability were recorded for seed yield (99.98) followed by plant height (98.78), thousand seed weight (98.29), days to 50\% flowering (97.17), days to maturity (85.57), pod length (85.11), grain filling period (82.79) and number of seeds per pod (68.01). Similarly, Manggoel et al. (2012), Thorat and Gadewar (2013), Khan et al. (2015), Khanpara et al. (2016), Reshma et al. (2019) and Mofokeng et al. (2020) reported high heritability values in cowpea.

\section{Expected genetic advance for selection}

Genetic advance is a measure of predetermined progress under artificial selection program. According to Jonhson et al. (1955) the value of GAM is categorized as low (<10\%), moderate $(10-20 \%)$ and high (> 20\%). In this study, the highest GAM was recorded for seed yield (100\%) followed by 100 -seed weight (68.16\%), grain filling period (39.65\%), pod length $(31.25 \%)$, days to flowering $(30.05 \%)$ and plant height $(28.42 \%)$, indicating that these traits are governed by additive genes and selection will be rewarding for improvement of cowpea for these traits. In agreement with the current study, high GAM for days to flowering, number of branches, pod number per plant, pod weight per plant, seed number per pod, hundred seed weight, seed number

per plant and seed yield (Mofokeng et al., 2020); number of pods per plant and 100 seed weight (Hermes et al., 2018); pod weight, number of pods per plant, days to $50 \%$ flowering, and number of seeds per pod (Khanpara et al., 2016; Hermes et al., 2018); number of branches per plant, 
plant height, pod yield per plot, total number of pods per plant and number of seeds per pod (Srinivas et al., 2017) were reported in cowpea.

Furthermore, high heritability coupled with genetic advance were recorded for days to flowering, grain filling period, plant height, pod length, seed yield and thousand seed weight, indicates additive gene action control the expression inheritance of these traits in cowpea (Ubi et al., 2001). A similar result was reported by Thorat and Gadewar (2013), Sharma et al., (2017) and Das et al. (2018) for seed yield and Khan et al. (2015) for the number of pods per plant and Reshma et al. (2019) for plant height, seed yield per plant, number of pods per plant, pod length and hundred seed weight in cowpea. High values for heritability coupled with high genetic advance for studied agronomic traits Overall, the estimates of heritability $\left(\mathrm{H}_{2}\right)$, genetic advance as percent of mean (GAM); genotypic coefficients of variation (GCV) and phenotypic coefficient of variation $(\mathrm{PCV})$ were high for seed yield and thousand seed weight which are critical to identify potential for development of superior cowpea genotypes and/or improvement of population through selection. 
Table 2: Estimates of phenotypic and genotypic variances and coefficient of variations, heritability in broad sense, genetic advance and genetic advance as percent of mean

\begin{tabular}{|c|c|c|c|c|c|c|c|c|c|c|}
\hline Traits & $\mathrm{MSg}$ & $\operatorname{MSe}\left(\sigma_{2} \mathrm{e}\right)$ & Mean & $\sigma_{2} g$ & $\sigma_{2} p$ & GCV\% & PCV\% & $\mathrm{H}_{2} \%$ & GA & GAM\% \\
\hline DF & $247.04 * *$ & 2.37 & 61.04 & 81.55 & 83.93 & 14.80 & 15.01 & 97.17 & 18.34 & 30.05 \\
\hline GFP & $93.29 * *$ & 6.04 & 25.50 & 29.08 & 35.13 & 21.15 & 23.25 & 82.79 & 10.11 & 39.65 \\
\hline $\mathrm{DM}$ & $112.8 * *$ & 6 & 86.53 & 35.60 & 41.60 & 6.90 & 7.45 & 85.57 & 11.37 & 13.14 \\
\hline $\mathrm{PH}$ & $567.3^{* *}$ & 2.32 & 98.87 & 188.33 & 190.65 & 13.88 & 13.96 & 98.78 & 28.10 & 28.42 \\
\hline PL & $15.91 * *$ & 0.88 & 13.61 & 5.01 & 5.89 & 16.44 & 17.82 & 85.11 & 4.25 & 31.25 \\
\hline NSP & $5.82 * *$ & 0.79 & 11.61 & 1.68 & 2.47 & 11.16 & 13.53 & 68.01 & 2.20 & 18.96 \\
\hline SY & $1770599 * *$ & 126.51 & 1574.15 & 590157.45 & 590283.96 & 48.80 & 48.81 & 99.98 & 1582 & 100 \\
\hline TSW & $4256.39 * *$ & 24.48 & 112.55 & 1410.63 & 1435.12 & 33.37 & 33.66 & 98.29 & 76.71 & 68.16 \\
\hline
\end{tabular}

$*, * *=$ significant at $\mathrm{P} \leq 0.05$ and $\mathrm{P} \leq 0.01$, respectively.

Where: $\mathrm{DF}=$ days to flowering, GFP = grain filling period, DM = days to maturity, $\mathrm{PH}=$ plant height, $\mathrm{PL}=$ pod length, $\mathrm{NSP}=$ number of seeds per pod, SY = seed yield, TSW = thousand seed weight; MSg = mean square of genotypes, MSe = mean square of error (environmental variance, $\delta_{2} \mathrm{e}$ ), $\sigma_{2} \mathrm{~g}=$ genotypic variance, $\sigma_{2} \mathrm{p}=$ phenotypic variance, $\mathrm{PCV}=$ phenotypic coefficient of variance $(\%), \mathrm{GCV}=$ genotypic coefficient of variance $(\%), \mathrm{H}_{2}=$ broad sense heritability $(\%), \mathrm{GA}=$ Genetic advance and GAM = genetic advance as percent of mean $(\%)$. 


\section{Genetic Divergence and Clustering of Accessions}

The tested accessions were grouped in four different clusters with the number of accessions per cluster varying from 6 to 16 (Table 3). The covariance matrix gave hierarchical clustering using average linkage method and the appropriate number of clusters was determined from the values of Pseudo F and Pseudo T2 statistics among 42 cowpea accessions (Table 4). Cluster I was the largest cluster comprising 16 accessions, followed by clusters II and IV that contained 10 and 10 accessions, respectively, where cluster III contained the smallest accession (6) number. Of the 16 accessions grouped in cluster I, 43.75\%, 25\%, 12.5\%, 12.5\% and 6.25\% of accessions originated from Oromia, Tigray, Amhara, SNNP and Gambella regions, respectively.

Similarly, in cluster II 50\%, 20\%, $20 \%$ and 10\%; cluster IV 40\%, 30\%, $20 \%$ and $10 \%$ of the total accessions grouped in the second largest clusters (Cluster II and IV) had in that order origins that are Gambella, B/Gumuz, SNNP and Oromia; Amhara, Oromia, Tigray and SNNP while the least of accessions (6) grouped in cluster III, 66.66\%, 16.67\% and 16.67\% were originated from Amhara, Gambella and B/Gumuz regions of Ethiopia, respectively (Table 4). The cowpea accessions originating from the same regions entered into different clusters indicating the absence of relationships between genetic diversity and geographic origin. For instance, the accessions from Oromia, Amhara, SNNP, Tigray Gambella and B/Gumuz regions of origin grouped into the four distinct clusters (Tables 3 and 4).

The main reasons for the grouping of accessions of the same origin into different clusters could be the exchanges of germplasm by farmers among neighboring regions, natural and artificial selection, genetic enrichment, genetic drift and environmental variation. Furthermore, Tesfaye $e t$ al. (2019) reported no relationship between genetic origin and /or diversity and geographic distribution

Table 3: Distribution of 42 cowpea accessions in 4 different clusters

\begin{tabular}{llllll}
\hline Region & \multicolumn{2}{c}{ № of accessions per cluster with respective percentage } & Total № of \\
\cline { 2 - 5 } & I & II & III & IV & accessions \\
\hline Oromia & $7(43.75 \%)$ & $1(10 \%)$ & 0 & $3(30 \%)$ & 11 \\
Amhara & $2(12.50 \%)$ & 0 & $4(66.66 \%)$ & $4(40 \%)$ & 10 \\
Gambella & $1(6.25 \%)$ & $5(50 \%)$ & $1(16.67 \%)$ & 0 & 7 \\
Tigray & $4(25 \%)$ & 0 & 0 & $2(20 \%)$ & 6 \\
\hline
\end{tabular}




\begin{tabular}{llllll}
\hline SNNP & $2(12.50 \%)$ & $2(20 \%)$ & 0 & $1(10 \%)$ & 5 \\
B/Gumuz & - & $2(20 \%)$ & $1(16.67 \%)$ & 0 & 3 \\
Total & 16 & 10 & 6 & 10 & 42 \\
$\begin{array}{l}\text { \% of clusters } \\
\text { Origin of }\end{array}$ & 38.10 & 23.80 & 14.30 & 23.80 & 100 \\
accessions & $1-5$ & $1,3,5,6$ & $2,3,6$ & $1,2,4,5$ & \\
\hline
\end{tabular}

1= Oromia, $2=$ Amhara, $3=$ Gambella, $4=$ Tigray, $5=$ SNNP, $6=\mathrm{B} /$ Gumuz

Table 4: List of cowpea accessions in each of the four different clusters

\begin{tabular}{cllll}
\hline Cluster & \multicolumn{4}{c}{ Accessions } \\
\hline I & Adongor & Acc\#223402 & Acc\#230575 & Acc\#228624 \\
& Acc\#26060 & Acc\#221727 & Acc\#223403 & Acc\#210857 \\
& Acc\#211446 & Acc\#211441 & Acc\#208776 & Acc\#26059 \\
& Acc\#211430 & Acc\#227104 & Acc\#211440 & Acc\#216746 \\
\hline II & Acc\#216749 & Acc\#216748 & Acc\#215821 & Acc\#216747 \\
& Acc\#211491 & Acc\#210856 & Acc\#211447 & Acc\#29597 \\
& Acc\#222891 & Acc\#211429 & & \\
\hline III & Acc\#222890 & Acc\#211433 & Acc\#211436 & Acc\#215761 \\
& Acc\#215760 & Acc\#211383 & & \\
\hline IV & Acc\#20864 & Acc\#215762 & Acc\#211557 & Acc\#211384 \\
& Acc\#235122 & Acc\#26058 & Bekur & Acc\#211443 \\
& Acc\#211444 & Acc\#211490 & & \\
\hline
\end{tabular}

\section{Mean performance of clusters}

The mean values of 8 agronomic traits per cluster are presented on Table 5. In this study, the mean values varied among clusters for the traits studied. Accessions those took longer days to flowering, maturity, plant height and extended grain filling period were found in cluster III. Cluster IV exhibited maximum mean values for pod length, seed yield and thousand seed weight. On the contrary, no significant variation was recorded among clusters for number of seeds per pod.

On the basis of overall mean performance, cluster IV showed the best performance for most important traits including seed yield. Therefore, cluster IV would be preferable for selection of parents with high mean values for the improvement of accessions. Conversely, cluster III had minimum values for yield and yield related traits. It showed the poorest performance of traits while the highest plant height was recorded in this cluster. Therefore, this cluster is preferable for increasing number of pods per peduncle. In general, there was highly significant variation in mean performance among the clusters for most of the traits, and this offers a huge opportunity to 
select potential parents across the clusters for specific traits for future cowpea improvement program. Overall, the variation observed among the 42 cowpea accessions suggests that agronomic traits can reveal diversity existing among cowpea genotypes. Molosiwa et al. (2016), Moolendra et al. (2018) and Tesfaye et al. (2019) had also reported similar results.

Seed yield and thousand seed weight were the major contributors for genetic divergence to the entire accessions (Table 5) while days to flowering, grain filling period, and days to maturity, plant height, pod length and number of seeds per pod had small contribution towards genetic divergence. In agreement with the study; Tesfaye et al. (2019) classified the levels of trait contribution for inter cluster divergence for cowpea $\geq 15 \%$ as high contributor, $\geq 8 \%<15 \%$ as medium contributor and $<8 \%$ as little contributor for inter cluster divergence in Ethiopia.

Table 5: Mean performance of cowpea accessions grouped into four clusters based on 8 agronomic traits

\begin{tabular}{llllllll}
\hline \multirow{2}{*}{\multicolumn{1}{c}{ Traits }} & \multicolumn{9}{c}{ Cluster } & & \multicolumn{2}{c}{ CTIC } \\
\cline { 2 - 5 } \multicolumn{1}{c}{} & I & II & III & IV & Mean & SD & $(\%)$ \\
\hline Days to flowering & 58.72 & 60.75 & 72.17 & 58.35 & 62.500 & 1.572 & 2.515 \\
Grain filling period & 27.09 & 25.82 & 19.22 & 26.38 & 24.630 & 1.530 & 6.212 \\
Days to maturity & 85.81 & 86.57 & 91.39 & 84.73 & 87.130 & 5.589 & 6.415 \\
Plant height & 95.34 & 104.13 & 111.57 & 91.67 & 100.680 & 1.177 & 1.169 \\
Pod length & 12.07 & 14.75 & 12.49 & 15.62 & 13.730 & 0.661 & 4.814 \\
Number of seeds per pod & 11.61 & 11.63 & 11.95 & 11.38 & 11.640 & 0.663 & 5.696 \\
Thousand seed weight & 99 & 113 & 100 & 141.2 & 113.300 & 17.02 & 15.02 \\
Seed yield & 1116.67 & 1850.30 & 520.20 & 2662.3 & 153.737 & 99.45 & 64.69 \\
\hline
\end{tabular}

CTIC $=$ Contribution to inter-cluster divergence

\section{Inter-cluster distance}

The dendrogram (Figure 2) showed that the accessions in this study could be valuable sources of genetic variability in cowpea breeding programs. The square distances ( $\left.\mathrm{D}_{2}\right)$ values (Table 6) revealed highly significant variation $(\mathrm{P} \leq 0.01)$ between clusters (inter), indicating wide diversity among accessions in the four different clusters. The highest average inter-cluster distance was recorded between the cluster III and IV ( $\mathrm{D}_{2}=133.69$ units) followed by the cluster I and IV ( $\mathrm{D}_{2}=69.39$ units), cluster II and III ( $\mathrm{D}_{2}=49.86$ units) while the lowest was between cluster I and II ( $\mathrm{D}_{2}=15.25$ units). Overall, the present study indicates that the accessions in cluster III and V were more diverged than any one of the other clusters while the nearest inter-cluster distance between cluster I and II were not genetically diverse. Thus, the accessions belonging to the 
distant clusters could be used for cowpea breeding program to get a wider range of variability in the segregating F2 population.

Table 6: Inter cluster distance ( $\left.\mathrm{D}_{2}\right)$ values among 42 cowpea accessions by the 8 agronomic traits

\begin{tabular}{|c|c|c|c|c|}
\hline Cluster & I & II & III & IV \\
\hline \multicolumn{5}{|l|}{$\mathrm{I}$} \\
\hline II & $15.25 *$ & & & \\
\hline III & $16.89 * *$ & $49.86 * *$ & & \\
\hline IV & $66.39 * *$ & $21.55 * *$ & $133.69 * *$ & \\
\hline
\end{tabular}

$* * *$ indicates significance at 0.05 and 0.01 level of significance; Chi-square $\left(\chi^{2}\right)=14.07$ and 18.48 at 0.05 and 0.01 , probability level, respectively.

Figure 2. Dendrogram showing clusters 1 - 4 using the 8 traits of 42 cowpea accessions

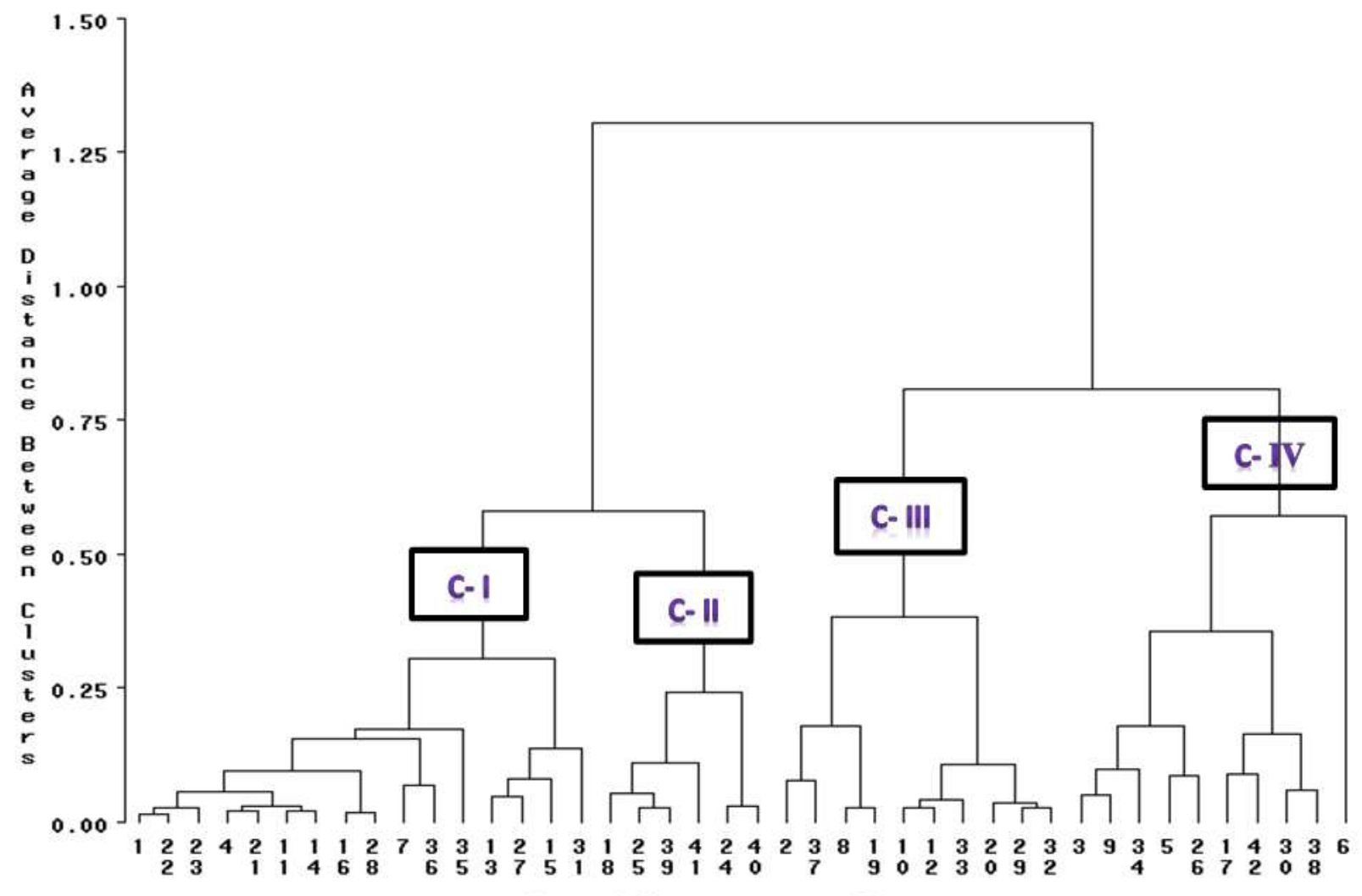

Name of Observation or Cluster

\section{CONCLUSION}

The result of the study revealed the existence of significant $(\mathrm{p}<0.01)$ genetic variability among Ethiopian cowpea landraces. Seed yield had higher genotypic coefficient of variation (GCV) and phenotypic coefficient of variation (PCV) coupled with the highest genetic advance as percent of 
mean (100\%). Further, high heritability coupled with high genetic advance as percent of mean was recorded for days to flowering, grain filling period, plant height, pod length, seed yield and thousand seed weight reflecting the presence of additive gene action for the expression of these traits and improvement of these traits could be done through selection. The cluster analysis based on agronomic traits revealed four distinct groups at $90 \%$ similarity level. The highest inter cluster $\mathrm{D}_{2}$ was recorded between cluster III and cluster IV ( $\mathrm{D}_{2}=133.69$ units). The range of inter cluster distance was 15.25 to 133.69 units, respectively. Therefore, based on the present findings, it can be conclude that the high genetic distance revealed among clusters has to be exploited via crossing and selection of the most divergent parents for future cowpea improvement program.

\section{CONFLICT OF INTEREST}

The authors have not declared any conflict of interest.

\section{ACKNOWLEDGEMENTS}

The authors thank Abergelle Agricultural Research Center for funding the research study. They also express their great gratitude to researchers of the center for devoting their time to effectively support this work. 


\section{REFERENCES}

Allard RW (1960). Principles of plant breeding. New York; John Wiley and Sons Inc. 485 pp.

Burton GW, DeVane EM (1953). Estimating heritability in tall fescue (Festuca arundinaceae) from replicated clonal material. Agron. J., 45:478-481.

Collaborative Crop Research Program (CCRP) (2015). Collaborative Crop Research program. Cowpea stallholder workshop, Accra, Ghana

Das, R. R., P. Talukdar, Praveen Kumar and S. B. Neog (2018). Relationship among different secondary traits and seed yield in cowpea (Vigna unguiculata L. Walp). Internationl Journal of Current Microbiology and Applied Sciences 7(2): 1382-1396.

Deshmukh S.N., Basu M.S. \& Reddy P.S. 1986. Genetic variability, character association and path coefficient analysis of Quantitative traits in Viginia bunch varieties of ground nut. Indian Journal of Agricultural Science, 56:515-518.

Diouf D and KW Hilu. 2005. Microsatellites and RAPD markers to study genetic relationships among cowpea breeding lines and local varieties in Senegal. Genetic Resources and Crop Evolution, 52:1057-1067.

Dwevedi KK and GM Lal. 2009. Assessment of genetic diversity of cultivated chickpea (Cicer arietinumL.). Asian Journal of Agricultural Science, 1(1):7-8.

Fantaye Belay, Atsbha Gebresilasie, Hintsa Meresa. 2017. Agronomic Performance Evaluation of Cowpea [Vigna unguiculata (L.) Walp] Varieties in Abergelle District, Northern Ethiopia. Journal of Plant Breeding and Crop Science, 9(8): 139-143.

Hermes AT, Carlos CA, Miguel EC, Darlin AP, Andrea GB. 2018. Estimation of genetic parameters in white seed cowpea (Vigna unguiculata (L) Walp). Austr J of Crop Sci. 12:1016-1022.

IBPGR. 1983. International Board for Plant Genetic Resources. Descriptors for Cowpea. Rome, Italy.

Jivani DR, MS Mehta, RB Pithia, C Madariya, and K Mandavia.. 2013. Variability analysis and multivariate analysis in chickpea (Cicer arietinum L.). Electronic Journal of Plant Breeding, 4(4)1284-1291.

Johnson HW, Robinson HF, Comstock RE. 1955. Estimation of genetic and environmental variability in soybeans. Agron J. 47:314-318.

Khan, H., Viswanatha K. P. and H. C. Sowmya (2015). Study of genetic variability parameters in cowpea (Vigna unguiculata L. walp.) germplasm lines. The Bioscan 10 (2): 747-750.

Khanpara SV, Jivani LL, Vachhani JH, Kachhadia VH. 2016. Genetic variability, heritability and genetic advance studies in vegetable cowpea [Vigna unguiculata (L.) Walp.]. Electr J Plant Breed. 7:408-411. 
Mahalanobis PC. 1936. On the generalized distance in statistics. Proceeding of National Academic of Science, 2:49-55.

Maletsema Alina Mofokeng, Jacob Mashilo, Paul Rantso \& Hussein Shimelis (2020): Genetic variation and genetic advance in cowpea based on yield and yield-related traits, Acta Agriculturae Scandinavica, Section B- Soil \& Plant Science, DOI:10.1080/09064710.2020.1749295.

Manggoel W., Uguru M. I., Ndam O. N. and Dasbak M. A. 2012. Genetic variability, correlation and path coefficient analysis of some yield components of ten cowpea [Vigna unguiculata (L.) Walp] accessions. Journal of Plant Breeding and Crop Science, 4(5): 80-86.

Menssena M, L Marcus, OO Emmanuel, AO Mary, FD Fekadu, and W Traud. 2017. Genetic and morphological diversity of cowpea (Vigna unguiculata(L.) Walp.) entries from East Africa. Scientia Horticulturae, 226:268-276.

Milligan GW and MC Cooper. 1985. An examination of procedures for determining the number of cluster in data set. Psychometrika, 50(2):159-179.

MoANR (Ministry of Agriculture and Natural Resource). 2016. Plant and Animal Health Regulatory Directorate. Crop variety register issue No. 20. Addis Ababa, Ethiopia.

Molosiwa OO, G Chiyapo, M Joshuah, and MC Stephen. 2016.Phenotypic variation in cowpea (Vigna unguiculata [L.] Walp.) germplasm collection from Botswana. International Journal of Biodiversity and Conservation, 8(7):153-163.

Moolendra, S Triveni, M Anjali, and T Neeraj. 2018. Morphological based genetic diversity studies of cowpea. Plant Archives, 18:227-231.

Omoigui LO, Ishiyaku MF, Kamara AY, Alabi SO, Mohammed SG (2006). Genetic variability and heritability studies of some reproductive traits in cowpea [Vigna unguiculata (L.) Walp.]. Afr. J. Biotechnol., 5(13):1191-1195

Ragab DD, EE Babiker, and AH Eltinay.2004. Fractionation, solubility and functional properties of cowpea (Vigna unguiculata) proteins as affected by $\mathrm{pH}$ and/or salt concentration. Journal of Food Chemistry, 84:207-212.

RavelombolaWS, AN Shi, YJ Weng, D Motes, PY Chen, V Srivastava, and C Wingfield. 2016. Evaluation of total seed protein content in eleven Arkansas cowpea [Vigna unguiculata (L.) Walp.] lines. American Journal of Plant Sciences, 7:2288-2296.

Reshma Krishnan, Lovely B. and Suja G. 2019. Genetic Variability and Heritability Studies in Cowpea (Vigna Unguiculata (L.) Walp). International Journal of Agricultural Science and Research, 9(4): 311-316. 
SAS Institute Inc. (2010). Statistical Analysis System, Version 9.2 SAS institute Inc.

Selamawit Ketema, Bizuayehu Tesfaye, Gemechu Keneni and Berhanu Amsalu. 2020. Genetic diversity for immature pod traits in Ethiopian cowpea [Vigna unguiculata (L.) Walp] landrace collections. African Journal of Biotechnology, 19(4):171-182.

Sharama JR. 1998. Statistical and Biometrical Techniques in Plant Breeding. New Delhi, India.

Sharma, M., P. P. Sharma, B. Upadhyay, H. L. Bairwa and D. R. Meghawal (2017). Character association and path analysis in cowpea [Vigna unguiculata (L.) Walp] Germplasm Line. International Journal of Current Microbiology and Applied Sciences.6 (6): 786-795.

Singh B.D. 2001. Plant Breeding: Principles and Methods 6th ed. Kalyani Publishers, New Delhi, India.

Singh R.K. \& Chaundry B.D. 1985. Biometrical Methods in Quantitative Genetic Analysis. 2nd ed., Kalayani Publishers, New Delhi-Ludhiana.

Srinivas J, Kale VS, Nagre PK. 2017. Evaluation of different cowpea varieties and genotypes. Int J Pure Appl Biosci. 5 (3):329-334.

Srivastava S, Ak Chopra, P Sharma, and V Kumar. 2016. Amendment of sugar mill waste water irrigation on soil bio hydrological properties and yield of [Vigna umguiculata(L.) Walp.] in two seasons. Communication in Soil Science and Plant Analysis, 48(5):511-523.

Tariku Simion. 2018. Breeding Cowpea Vignaunguiculata 1. Walp for Quality Traits. Ann Rev Resear, 3(2): 555609.

Tesfaye Walle, Firew Mekbib, Berhanu Amsalu and Melaku Gedil. 2019. Genetic Diversity of Ethiopian Cowpea [Vigna unguiculata (L) Walp] Genotypes Using Multivariate Analyses. Ethiopian J. Agric. Sci., 29(3): 89-104

Thorat, A. and Rajesh D. Gadewar. (2013). Variability and correlation studies in cowpea (Vigna unguiculata). International Journal for Environmental Rehabilitation and Conservation, 4 (1): 44-49.

Timko MP and BB Singh. 2008. Cowpea, a multifunctional legume. Genomics of Tropical Crop Plants, 227-257.

Ubi EB, Mignouna H, Obigbesan G. 2001. Segregation for seed weight, pod length and days to flowering following cowpea cross. Afr Crop Sci J. 9:463-470.

Vavilov, N.I. 1951. The origin, variation, immunity and breeding of cultivated plants. Chronica. Botanica, 13 (1-6):1-36.

Ward JR. 1963. Hierarchical grouping to optimize and function. Journal of American Statistical Association, 58(301):236-244. 
Figures

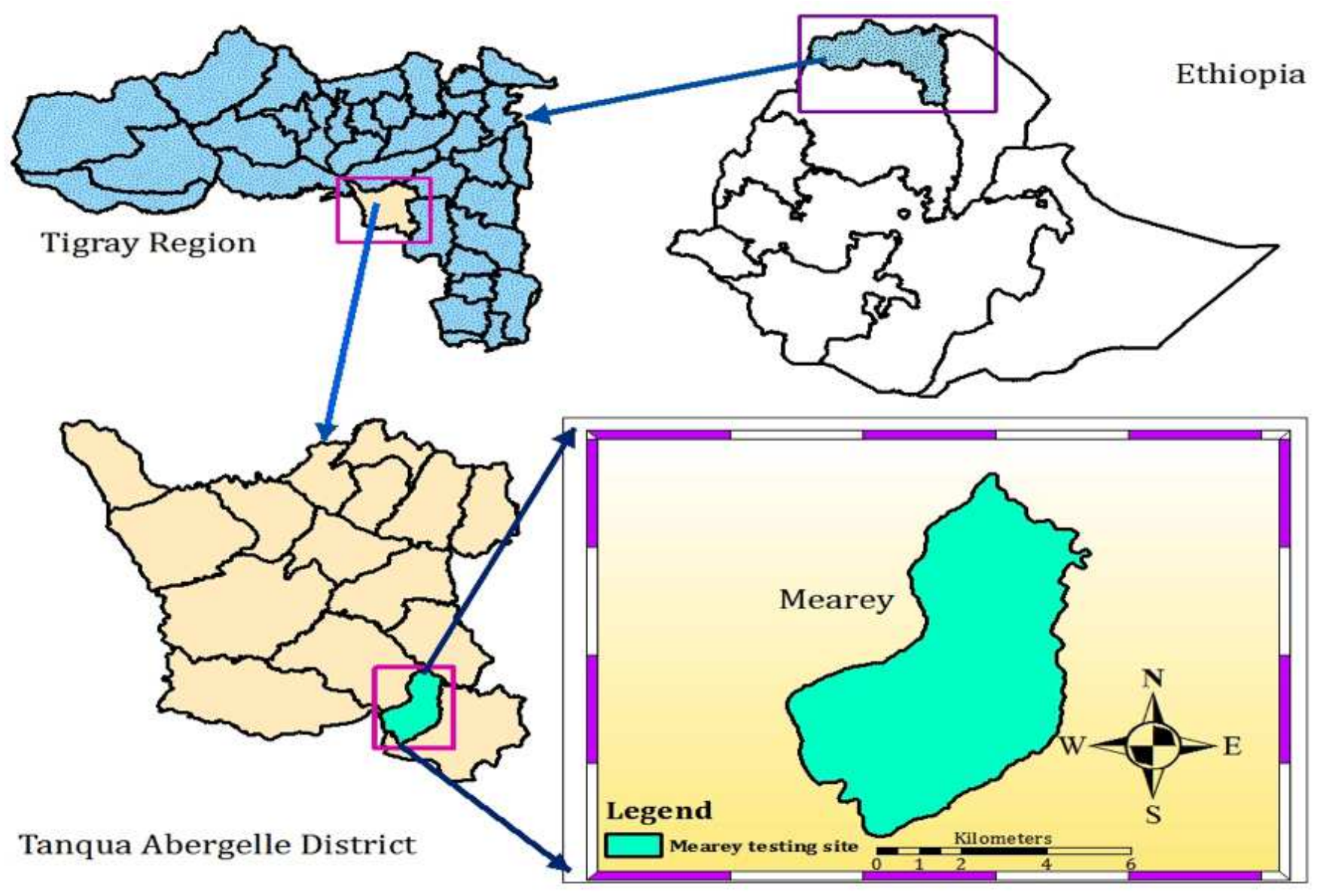

Figure 1

Map of the study site 


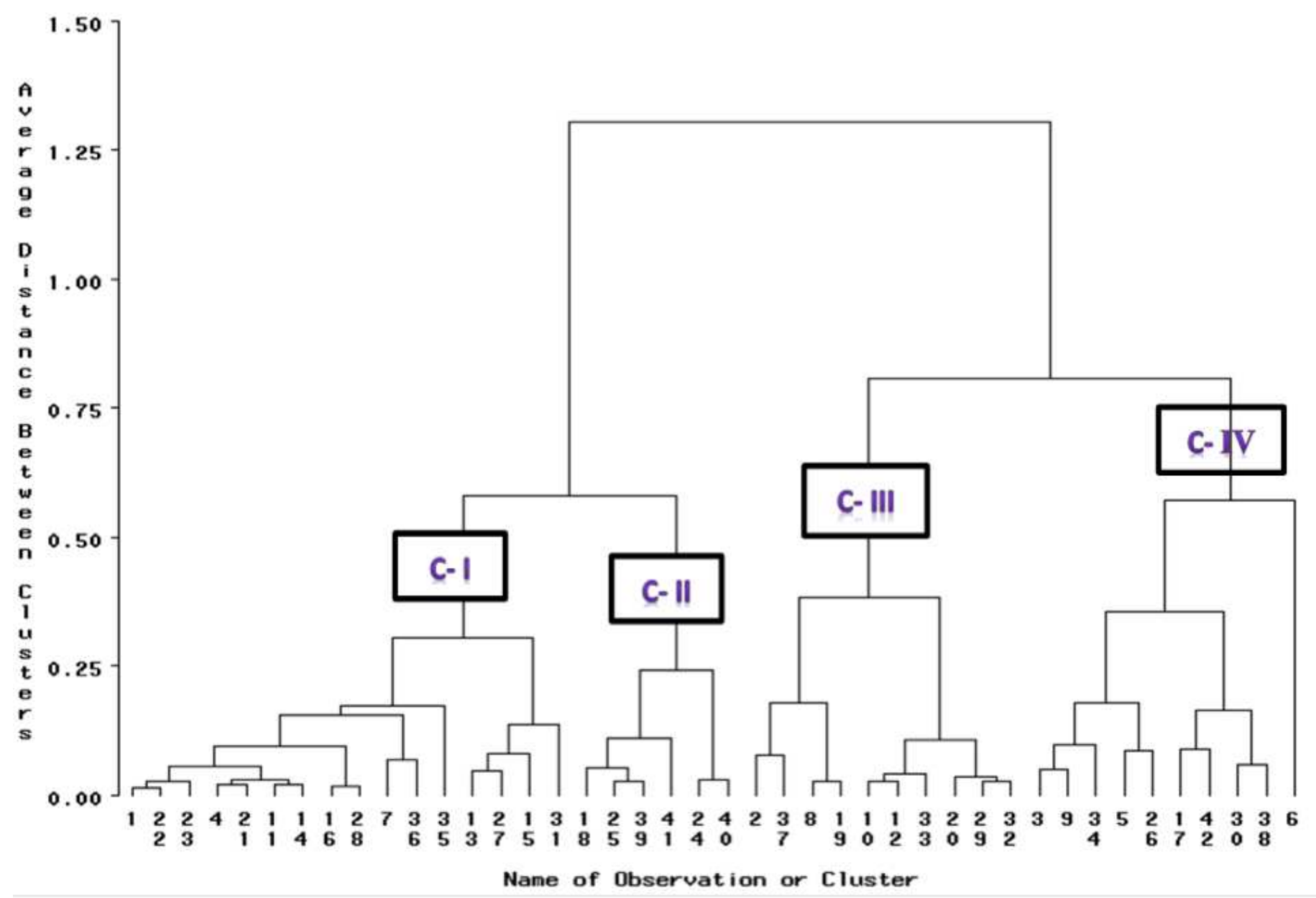

Figure 2

Dendrogram showing clusters 1 - 4 using the 8 traits of 42 cowpea accessions 